\title{
Por uma ciência livre da política de abolir a política
}

\section{For a science free of the politics to abolish the politics}

\author{
Moisés Alves de Oliveira ${ }^{1}$
}

\section{Resumo}

O objetivo deste texto é (ex)por historiograficamente algumas idéias acerca da encruzilhada na qual o pensamento científico (razão) e a idéia de cidadania (política) parecem ganhar suas distinções. A narrativa se dará pela busca da articulação de três tempos distintos. A) A atualidade: na qual a âncora é a controvérsia acerca de combustíveis renováveis. B) A instituição da racionalidade e da certeza absoluta carteziana e C) Os acordos forjados por Platão para justificar a idéia de cidadania. No final do texto, discute-se a própria concepção de pensamento científico. $\mathrm{O}$ pano de fundo teórico articula-se às considerações relativistas de Bruno Latour, em particular o conceito de "matérias de interesse".

Palavras-chave: Matérias de interesse. Pensamento científico. Biodiesel.

\begin{abstract}
The purpose of this text is to present historiographically some ideas about the crossroads where the scientific thought (reason) and the idea of citizenship (politics) seem to acquire their distinctions. The narrative will be carried out by means of the search for the articulation of three distinct periods of time: A) the present: in which the anchor is the controversy about renewable fuel. B) The institution of rationality and the absolute cartesian certainty and C) Plato's forged agreements to justify the idea of citizenship. At the end, a discussion about the scientific thought is carried out. The theoretical background is connected to the relativistic considerations by Bruno Latour, in particular the concept of "matters of interest".
\end{abstract}

Key words: Matters of interest. Scientific thought. Biodiesel.

\section{Introdução}

Guerras. Muitas guerras. Guerras externas e internas, guerras culturais, guerras das ciências, guerras contra a pobreza, guerra contra os pobres, guerra contra a ignorância, guerra dos ignorantes... é assim que o filósofo sociólogo e antropólogo francês Bruno Latour inicia seu texto em que propõe um "segundo empirismo" fundamentado não em fatos mas em matérias de interesse (LATOUR, 2004).
Mas qual seria a vantagem de insistir na produção da ciência como um trabalho coletivo de matérias de interesses, em vez de permanecermos nas confortáveis definições da ciência como a sucessão histórica de fatos? Essa pergunta tem sido uma preocupação para nós. Com efeito, ela problematiza uma questão de maior importância para o entendimento das atividades científicas, pois busca superar a idéia de que o problema do conhecimento deva ser distinguido da questão política e social. Tal preocupação alinha-se mais fortemente ao que

\footnotetext{
Professor Adjunto do Departamento de Química, área de Ensino de Química, Universidade Estadual de Londrina, - UEL. moises@uel.br
} 
se vem chamando de Estudos Culturais da Ciência (ECC), mais especificamente à perspectiva de que não é possível escapar da linguagem para atingir diretamente a natureza de um fato (GRAY, 2006; LATOUR, 2001; LATOUR, 2004a; LENOIR, 2005; WORTMANN; VEIGA-NETO, 2001).

Pensar na natureza do fato pela perspectiva cultural tem um sentido bastante diverso do realismo inventado no século 17 (MONDIN, 1981), em torno da definição de fato indisputável, por uma razão até bastante simples, não é isso o que se pratica como ciência. Tornar seus "fatos" disputáveis é a atividade que os cientistas mais se ocupam, é o que garante que a conversa não cesse, que os financiamentos sejam aprovados, que a ciência cada vez mais se consolide como importante obra humana (pelo menos aquelas obras que interessam). Cabe considerar, porém, que ao contrário dos argumentos realistas de outrora, os fatos não estão carimbados como natureza nas coisas. Não é mais possível partir do pressuposto de que um cientista fala "naturalmente", com autoridade e somente por isso convença facilmente as pessoas de sua força e importância a ponto destas lhes darem verbas, laboratórios e departamentos.

Antes que a "força" do cientista e a sua invenção se consolide como tal, todos são capazes de viver muito bem sem eles. A história recente é pródiga nisso: o computador, o celular e os biocumbustíveis, por exemplo. Nesse texto vamo-nos ater mais especificamente nesse último. O biocumbustível é uma vedete que assume, na retórica política, jornalística ecientífica uma força que até pouco tempo atrás estava restrita a alguns centros de pesquisa e alguns poucos e desconhecidos cientistas no Brasil. Sem poder convencer ninguém com seus resultados apenas parciais, tais cientistas permaneciam como se não existissem. Mas, pouco a pouco, passam a ser (cientistas e biocombustíveis) realidades cada vez mais inquestionáveis e intimamente conectados ao corpo social. Irresistivelmente necessários. Contudo no caso dos biocombustíveis, muitas agonísticas $^{2}$ ainda estão em andamento, o que faz dele uma importante matéria para os ECC, que tende a se ocupar mais intimamente com as análises dos processos de produção do que com os extremos já acabados e sem possibilidade de discussão (GROSSBERG, 1992; LATOUR, 1997). Analisar a ciência em ação é prestar atenção em detalhes do trabalho coletivo que faz da atividade científica um labor contingente. O fato científico é, nessa perspectiva, entendido como sempre ulterior à resolução das controvérsias (LATOUR, 2000).

Este é um ponto importante a ser tratado, a questão da ulterioridade, posto que é somente ao final de todo um processo, quando as conseqüências e matizes indesejáveis, a interferências de várias pessoas, interesses e as dúvidas estiverem dirimidas, que se pode dizer que algo é um fato (LATOUR, 2000). Para entender a ciência como parte da rede que constitui a sociedade, não faz sentido olhar para os fatos já instituídos, e não resta outra coisa a não ser aceitá-los. Latour ajuda nesse pensamento, ao atinar nas ações que constituem as negociações dentro do campo da pesquisa científica, como orientadas não para os objetivos em si, mas para as matérias de interesse, para as estratégias que se sucedem até que o fato obtenha sua realidade:

Uma vez que se admite que as ações dos pesquisadores são orientadas para o campo agonístico, pouco se ganha com a insistência na distinção entre a 'política' da ciência e sua 'verdade'. As mesmas qualidades 'políticas' são postas em operação para realizar um avanço e para pôr um concorrente fora de combate (LATOUR; WOOLGAR, 1997, p. 268).

\footnotetext{
2 A noção de agonística é um ponto de importância a ser visitado como ferramenta para o entendimento da atual condição da produção da ciência. Para Latour e Woolgar (1997, p. 267), "uma das vantagens da noção de agonística é que ela integra ao mesmo tempo várias características do conflito social (controvérsias, relações de força e alianças). Explica com olhares renovados os fenômenos descritos até aqui em termos epistemológicos (prova, fato e validade)". Na perspectiva pós-estruturalista, a agonística funciona não como o conceito que vai fazer a ponte entre sociedade, política e ciência, é antes o constituinte desses segmentos.
} 
Pensar na perspectiva da agonística, articulada ao conceito de interesse, remete-nos para a região mais quente e indefinida da ciência, aquela que ainda não pode ser chamada de fato, posto estar sendo produzida por muitas máquinas e pessoas, inclusive cientistas. Tomaremos como ponto de partida, este evento atual ${ }^{3}$ que busca reunir em concílio, cientistas, pesquisadores, políticos, ministros, mídia, povo... para decidir a quem cabem os louros acerca do biodiesel.

No dia 02 de outubro de 2004 a Folha de S. Paulo veiculou uma notícia em tom professoral, com o título: "BIODIESEL, entenda o que é!..." após a "aula científica", verteu as mais desejáveis vantagens sobre esse produto:

"Não é necessária nenhuma modificação nos
motores. É nacional e $100 \%$ renovável. Reduz a
emissão de gases poluentes. Reduz a dependência
do país em relação ao petróleo. Fortalece o
agronegócio..."

Na página 8 da Folha de S. Paulo, no dia 02 de outubro de 2004, pôde-se ver a manchete sangrenta com o título "Professor sofre atentado no campus da USP".

O presidente da Câmara Setorial de Biocombustíveis do Estado de São Paulo e professor de química orgânica da USP, Miguel Joaquim DabdoubPaz, sofreuumatentado a tiros anteontem à noite, dentro de um laboratório no campus da USP em Ribeirão Preto. Por volta das 21h30, quatro tiros de pistola foram disparados contra o professor, pela janela, mas ele conseguiu fugir sem ser atingido. O crime ocorreu dois dias depois que Dabdoub registrou um boletim de ocorrência dizendo ter recebido, por telefone, ameaças de ex- alunos, que participavam de pesquisas no Ladetel (Laboratório de Desenvolvimento de Tecnologias Limpas).Dabdoub disse que os alunos roubaram técnicas e informações confidenciais para criar uma empresa privada, a MB do Brasil. A partir dela, iriam negociar contratos com outras empresas para passar o conhecimento sobre o biodiesel produzido a partir da cana-de-açúcar. O professor também acusou a empresa Dedini, de Piracicaba, de "aliciar" os estudantes para obter o conhecimento do laboratório de maneira ilicita. A empresa e os alunos negam as acusações e dizem que vão processar o professor. [...] A MB, formada por ex-alunos do professor, diz que são "mentiras" e "calúnias".

Numa outra manchete:

"Pesquisa de alta tecnologia tem forte demanda e remunera bem. Salários para pesquisadores vinculados ao agronegócio passam dos $R \$ 7.000$ nas empresas de grande porte".

$\mathrm{Na}$ TV, um telejornal veiculou entrevista como o presidente do Conselho Regional de Engenharia e Arquitetura do Paraná, que fez uma estranha conexão entre ciência, tecnologia, política e humanismo. $\mathrm{O}$ presidente afirma estar empenhado em derrubar as leis estaduais que impedem que qualquer um possa fabricar biodiesel em seu quintal e assim libertar, de uma vez por todas, a submissão da maioria pela minoria que controla o sangrento jogo de interesses acerca dos combustíveis no mundo.

Nestas histórias estão envolvidos os mais diferentes personagens, unindo ciência de "exóticos" laboratórios universitários, ao mais "autêntico" jogo político, com direito a troca de acusações e tiros.

3 Os episódios relatados são de 2004, posto que esse artigo é uma versão ampliada e modificada de uma palestra proferida como abertura da X semana da Licenciatura Plena em Ciências, Goiorê, em 2004. Contudo, longe desse assunto ter se esgotado como construção está ainda na vanguarda dos interesses de vários grupos concorrentes. Veja por exemplo a reportagem de 18 julho de 2006 da folha de S. Paulo, "Chegou a hora de tirarmos as cartas dos nossos bolsos, afirma presidente a Bush", que narra a conversa do Presidente Lula com Bush em São Petersburgo em que tratam de uma parceria para o biodiesel. Ou a de 11 de julho de 2006, 'Em Lisboa, Alckmin fala em 'aprofundar inserção' do Brasil”, novamente o assunto atravessa o tema biodiesel.

4 "Matéria de interesse" é a expressão que Bruno Latour propõe para substituir "matérias de fato". "Matérias de fato são indiscutíveis, matérias de interesse são altamente discutíveis; matérias de fato não tinham conseqüências, matérias de interesse têm um monte de conseqüências indesejadas; matérias de fato eram produzidas em laboratórios fechados, matérias de interesse são produzidas por muitas outras pessoas do que apenas cientistas e industriais" (LATOUR, 2004a) . Latour defende que embora a ciência e a tecnologia estejam por toda parte na nossa vida cotidiana; a nossa filosofia da ciência e nossa concepção de tecnologia estão ultrapassadas para lidar com uma ciência e tecnologia tão amplamente espalhadas e tão intimamente conectadas com tantos outros debates, justamente por se aterem aos fatos imutáveis e não aos interesses que constituem os fatos. 
Assim, basta uma olhada nos jornais para que essas "matérias de interesses" olhos e enfraqueçam de imediato qualquer idéia de "ciência desinteressada". Mesmo assim, a "epistemologia (política)", os jornalistas e os livros didáticos insistem em cortar em quantas partes for necessária a confusão humana, até que se tornem "matérias de fato" isolados e sem nenhuma conexão possível. "Não vamos misturar céu e terra, o global e o local, a razão com a política dizem eles". (LATOUR, 2004a, p.30). É como se um fosso de formasse entre dois universos em constante conflito. De um lado, está o dedicado professor/pesquisador em seu laboratório na USP, isolado de tudo e produzindo uma ciência pura, imaculada. Do outro, a turba, incluindo seus ex-alunos e presidentes, como aves de rapina, tentando invadir por todos os meios possíveis o seu laboratório. De um lado, o conhecimento puro, do outro os interesses, o poder e a política dos homens.

Trazer para a discussão esses assuntos que envolveram a ciência universitária e cenas de banguebangue, não é para causar alguma surpresa para os que costumam olhar para os "fatos" já prontos e não para a sua construção; é antes, a busca por superar esse impasse; para tal, tomaremos a perspectiva dos ECC, naquilo que pode ser entendido como um ponto fundamental: assumir a não separação da ciência da suas condições humanas de produção. O exemplo do episódio na USP é panfletário, bem o sabemos, mas é útil para mostrar que não há um fosso que separa ciência dos jogos instintivos que outrora eram vistos como apenas da multidão ${ }^{5}$.

A ciência está de tal forma articulada à sociedade que bramir "na ciência não pode haver dúvida", não faz mais sentido, não há como se valer de uma epistemologia já desbotada que luta por manter o mais longe possível a ciência e a política. Ora, não se pode agir como se não houvesse o burburinho, as redes de interesses coletivos, a "multidão" agindo como criança, segundo interesses e conexões específicas. O que se vê é uma sociedade cada vez mais presente nas questões científicas e políticas. A busca por marcar simetricamente dois territórios distintos traz a idéia que fora deles nada poderia acontecer. Trata-se de uma estratégia tirada diretamente do cérebro cartesiano (LATOUR, 2001), e não tem outro objetivo senão o de convencer o maior número possível de pessoas, de que somente nas instâncias purificadas das extremidades: ciência de um lado, interesse de outro, pudesse acontecer algo importante.

O objetivo de apresentar este caso recente de nossa história, não é apresentar ao leitor coisas que já sabe, tampouco entraremos em pormenores acerca dessa controvérsia em particular, é apenas um ponto de partida para ensaiar uma discussão acerca da questão do fosso forjado entre conhecimento e crença, entre ciência e política, já que estes termos (conhecimento e crença) somente fazem sentido depois que as dúvidas e incertezas são dirimidas.

De forma modesta, tentaremos como metodologia, descrever como a circulação de interesses, conforme tratado por Latour (2001), funciona para contar e para produzir uma história, carregada de teorias e interesses vindos de outros contextos. Como disse Veiga-Neto ao se referir ao caráter monumental dos textos,

[...] jamais se coloca, [...] uma pergunta do tipo: "o quanto se afasta esse ou aquele autor, esse ou aquele texto de um verdadeiro ou de um melhor conceito". Isso significa que minhas leituras não fizeram a anatomia dos textos. Minhas leituras foram superficiais. Isso deve ser entendido, certamente, não como "apressadas" ou "não rigorosas", senão como leituras que são feitas pela superfície em que tais discursos se relacionam com a episteme em que nasceram e em que são pronunciados. Cada texto é um monumento que

\footnotetext{
5 Para este texto será utilizada uma distinção entre povo e multidão, com base em Michael e Negri (2003). Multidão toma o sentido de um aglomerado de humanos e não-humanos que se caracterizam pela pluralidade e heterogeneidade e que reagem de maneira específica e mais ou menos impulsiva aos estímulos. Enquanto povo tem outro sentido, o de corpo político, pessoas que constituem uma sociedade política ou vivem sob leis gerais (o cidadão).
} 
ocupa um espaço, empurrando para os lados os outros textos[...]. (VEIGA-NETO, 1996, p. 354.

As falas, os fragmentos históricos, as apresentações que estão sendo feitas são tomadas desta exterioridade à qual se refere Veiga-Neto, sempre negociada e esvaziada da origem e não na sua linearidade e internalidade documental. $\mathrm{O}$ que fizemos foi realizar análises fragmentárias e transformáveis utilizando-nos de alguns episódios da mídia e fazendo-os funcionar dentro de um sistema simbólico que envolveu um leitura interessada das posições de Platão e Descartes.

Seguindo Lê Goff (1992) e Gore (1994), nosso argumento é que devemos analisar os textos não como documentos, mas como monumentos fabricados segundo relações de poder que não são necessariamente repressivas, pois esses textos induzem, seduzem e tornam a tarefa mais fácil ou mais difícil, ampliam ou limitam, alinham os interesses ou destroem as possibilidades.

De fato, o noticiário de TV e os jornais não escondem o objetivo do governo e dos cientistas, quando dizem que estes buscam a independência nacional e fontes limpas e renováveis de energia. Nem é interesse dos ECC buscar qualquer sentido oculto, como diz Foucault (1999), não há nada fora da própria prosa do mundo. O que a perspectiva dos ECC busca é a série de operações e de translações de termos políticos e científicos. Para o Presidente da República, marcar pontos na corrida mundial pela liderança em tecnologias renováveis significa falar e apoiar a síntese orgânica e, para o pesquisador, demonstrar a viabilidade técnica de um combustível, implica, em parte, lidar com espiões e apoiar as relações internacionais entre países.

Analisar essas minúsculas atividades translativas constitui boa parte dos interesses dos ECC (WORTMANN, 2001, LATOUR, 2004b). De resto, a perspectiva dos ECC não é estabelecer ou destituir qualquer realidade ou fato, é antes pensar a ciência como objeto de estudos e acompanhar suas trajetórias enquanto está sendo produzida.
No exemplo que citamos acima, a existência de conexões entre as pesquisas na USP e o encontro do presidente Lula com o Presidente Bush (para falar nas possíveis parcerias para desenvolvimento de biocombustíveis), depende inteiramente do que está sendo feito para estabelecê-lo. Como diz Latour (2000) "os resultados da ciência dependem sempre do próximo passo", assim, a certeza é sempre o produto final de uma trajetória em que as negociações, os inúmeros testes de laboratório, os muitos estagiários treinados e rebelados vão sendo postos de lado para que somente o produto final retumbe no imaginário. $\mathrm{Na}$ concepção latouriana, vale lembrar, a certeza é sempre ulterior.

Problematizar, mesmo que de forma limitada e contingente a questão da crença na razão e na objetividade, bem como a estratégia de separar a ciência da política implica recair em mais uma "autoestrada" (SERRES, 1999), posto que assume-se aqui a postura de uma tribo de estudiosos que recusam qualquer oposição do conhecimento científico a outras produções culturais (WORTMANN; VEIGANETO, 2001). Por essa perspectiva, não interessam as designações científicas vindas de carona na pálida e sem sangue argumentação de "objetividade da ciência" que pouco a pouco se incorporou como uma tradição para distinguir a ação consciente, bem articulada e com a "boa intenção"; dos jogos políticos que a constituem. Nesta concepção de rede, o pesquisador isolado em seu laboratório, sem alunos, fornecedores e o interesse do governo, da mídia, - é possível dizer -, não produziria biodiesel algum.

O que se propõe então é descrever desses personagens vivos, carregados de paixão, ricos em conhecimentos práticos e imersos em um meio mais vasto e incerto do que se pode controlar. Chamaremos a esses atores cientistas. Todas essas características têm sido negadas por aqueles que, como o filósofo existencial Martin Heidegger, dizem que a ciência não pensa, ou dito de outro modo, necessita se afastar das perigosas massas disformes com suas atitudes não controláveis para poder pensar. Esta é uma forma um tanto bizarra e perigosa de se referir ao trabalho dos 
cientistas e não faz justiça às ciências, pois desconsidera o que Collins (1998), chama de determinações causais.

Mas para entender o jogo das matérias de interesse que envolvem a política e a ciência dos biocombustíveis, é preciso recuar alguns passos. E o faremos partindo de excertos mais recentes na história, em particular das influências de Descartes e, depois, em um salto cronológico, em direção ao passado, revisitaremos Platão.

Por primeiro iremos tratar da questão da separação entre o corpo ecológico e a mente racional. Fazendo um recuo ainda maior, no item "Os debates, a busca da razão que paira acima da discussão", será tratado o construto discursivo entre Sócrates e Cálicles, que visou a tornar impossível pensar a ciência e a política como invenções que podem conviver juntas. Para concluir, será lançada a idéia latouriana de que a ciência não funciona isolada do mundo, portanto não está aprisionada às definições de uma epistemologia política de ciência que somente olham para a ciência pronta e não a ciência vascularizada na teia social.

\section{A distinção entre mente e corpo}

Ao observar as idas e vindas de políticos, das negociações e os assaltos em torno do biocumbustível, fica cada vez mais difícil imaginar a ciência isolada das contradições que enriquecem o debate da vida comum. A idéia da ciência como a cultura legítima e consagrada para ajuizar as ações humanas em oposição à política ou que se chama de cultura de massa produzida pelas indústrias culturais (MATTELART, 2004), ressona tão estranha em nossos sentidos quanto a distinção evocada por Descates [1595-1650]. Esse autor, ao tentar criar a idéia de que uma mente isolada da natureza, da sociedade, conectando-se somente na razão, produz a idéia de uma perfeita simetria das formas geométricas - que não existe na natureza, mas é produzida na mente do homem -, e que só poderia ser a verdadeira amarração com Deus, e seria o único caminho para alcançar absoluta certeza sobre as coisas do mundo exterior (DESCARTES, 1989). Acreditar nesse pensamento cartesiano é transformar os sentidos que nos conectam com o mundo natural inadequados. Contudo, foram necessários três séculos para que percebêssemos, aos poucos, que não necessitamos estar, e nunca estivemos, totalmente seguros de muitos dos objetos e situações em que lidamos cotidianamente. Tampouco é necessário pensar em um cérebro (alma científica) extirpado de um corpo, como queria Descartes no século 17. A segurança absoluta cartesiana, que podemos chamar de certeza absoluta é chamada por Latour de "fantasia neurótica de uma mente cirurgicamente removida" (LATOUR, 2001, p. 16). Na mesma página Latour continua a afirmar que "somente alguém com medo de perder ambas, a sociedade e a certeza, poderia buscar fazer tal distinção entre a mente (conhecimento científico) e a política (o direito à cidadania e a sensação de pertencimento a uma dada sociedade)". Essa é uma questão central neste texto, reconhecer a hibridização e a controvérsia sobre o conteúdo da ciência supostamente entrincheirado nos laboratórios e o perfil dos públicos das quais elas mesmas são indissociáveis.

Que fazemos quando buscamos novamente encontrar as sendas encobertas por camadas de poeira e história, senão a busca desesperada por restabelecer as conexões do conhecimento científico ao resto do mundo. Nunca estivemos longe dele, a ciência nunca esteve "extirpada" do corpo social, pelo contrário, são constituintes desta mesma sociedade (LENOIR, 2005). Porque? Perguntariam alguns. Ainda sentimos necessidade de fazer esta (re)conexão, na qual encontramos a encruzilhada que afastou o conhecimento do resto do corpo social? Talvez esta seja uma má pergunta, talvez seja a própria pergunta que mantenha a insistência cartesiana: para alcançar o verdadeiro conhecimento científico, a mente extirpada do corpo deveria ir diretamente a Deus, e não à barafunda de crenças e ilusões do mundo (LATOUR, 2004a). O que Descartes tentava fazer era justamente estabelecer 
uma dicotomia entre a ciência e a política de fazer ciência. Ele buscava afastar o máximo possível o conhecimento científico, que podemos chamar de Ciência com "C" maiúsculo, do perigoso contágio da crença, da desorganização da multidão, que poderia a qualquer momento invadir seus castelos, digo, laboratórios, e levar-lhes as idéias e as coisas, como relatou na polícia nosso pesquisador. Esta era a proposta cartesiana para se chegar a um mundo natural, limpo, organizado e acessível, expurgado de qualquer contribuição, ainda que mínima, das faculdades sensitivas, já que aceitá-las seria minar seriamente a solidez do edifício científico.

Depois de Descartes, muitos perguntaram por que precisamos do artifício da Ciência, com "C" maiúsculo e completamente isolada para explicar e sobreviver no mundo. Também se questionou porque precisamos ir até Deus. Os empiristas disseram, "iluminados" pela crença na capacidade de conhecer, serem capazes de ir empiricamente ao mundo natural e de lá extrair tudo o que precisavam saber. Esta perspectiva empirista de tratar o conhecimento floresceu mais acentuadamente na Inglaterra do século 18, embalada pelo clima cultural que via a Botânica, a Química, a Astronomia, a Mecânica e a Ótica surgirem como ciências experimentais (LATOUR, 2001; LENOIR, 2005).

Para os empiristas, as ciências experimentais partem daverificaçãode acontecimentos particulares, da "experiência" de certos fatos concretos e não de idéias abstratas e princípios universais. De um modo resumido, o que queriam os Ingleses do século 18, tais como John Locke, era saber como é possível, partindo da experiência de fatos singulares, subir a leis universais de maneira a garantir o retorno seguro à esfera dos acontecimentos concretos, das experiências individuais. Ao partir para este caminho, os empiristas mantiveram sem alteração a natureza de um lado e a sociedade e suas políticas do outro, ao estabelecer o "estado da natureza", atribuindo-lhe uma lei geral chamada "razão". Este foi um impulso importante para o fortalecimento da idéia de uma sociedade civil. Pensar a incerteza, a instabilidade da capacidade humana de interpretar as formas pelas quais a "natureza" exerce seus poderes punitivos, fez surgir na mente dos empiristas a extrema importância de organizar a multidão com regras e leis. Locke (1998) diria que a mente humana não pode conhecer a essência das coisas, mas só a sua existência, porque sendo passivos em nossas sensações, temos que pensar em uma existência do mundo distinta de nós e que seja causa de nossas sensações.

Locke e sua tabula rasa não superam, ao contrário, continuam a estimular a idéia cartesiana, ao defender que o grande desafio era adestrar a mente para reconhecer esquemas. Nosso conhecimento não seria então mais do que o bombardeio de estímulos sem sentido, que o conhecimento trataria de organizar na forma de um mundo real.

Com os empiristas, a necessidade da certeza absoluta cartesiana foi em parte abandonada. Contudo, como disse Koyré (1982), ao provarem que suas idéias experimentais da natureza, quando não atrapalhavam eram irrelevantes, a inclinação experimental dos empiristas acabou demonstrando o quanto são precárias nossas conexões com o mundo exterior. No entanto, mantivemos firme a noção de que a mente tira de si mesma tudo o que necessita para construir formas e história. É isto que parece autorizar a falar com confiança acerca do conhecimento organizado: o conhecimento científico. É por isso que vemos os políticos discutindo apenas o "produto biodiesel" como fato. Sem levar em conta a situação, pessoas e juízos que constituíram, ao longo de uma trajetória, a produção do biodiesel. Por exemplo: a fala do presidente do Banco Mundial, Paul Wolfowitz, ao dizer à $\mathrm{BBC}$ Brasil "que o etanol brasileiro é de uma 'eficiência excepcional' e 'é fácil entender por que os biocombustíveis estão no topo da agenda do presidente Lula"' (FOLHA de S. PAULO, 2007). São falas que funcionam como assertivas, isto é, como discursos preparados para difundir fatos bem contornados e já livres dos intermediários e translações. Laboratórios, cientistas, corrupção universitária foram importantes enquanto o produto 
estava sendo produzido. Depois disso não há porque permanecer insistindo em controvérsias ou em técnicas de extração orgânica, aos políticos cabe utilizar, em sua política, as proposições da certeza, outrora atribuída somente às ciências, para difundir fatos, como diz Latour (2000, p. 221) com "uma vis inertia própria". Quando o produto se torna " a matéria de interesse" sua trajetória inicial não significa mais nada. Os biocombustíveis passam a funcionar desterritorializados, ou seja, ganham independência como fato, e parecem se mover sem a ajuda das pessoas para funcionarem em outros contextos.

A visita do presidente estadunidense ao Brasil com o discurso de parcerias nas pesquisas com biocombustíveis é um exemplo do quanto um produto científico se transformar em fato depende do poder dos interesses que estão em jogo. "[...] é fato que os EUA querem fortalecer o papel do governo Lula na América Latina como maneira de neutralizar a influência do presidente venezuelano na região [...]" (DÁVILA, 2007).

Não seria interessante para uma negociação internacional dizer das incertezas da ciência, que de resto, depois de solucionados os problemas, tampouco interessa aos cientistas. É nesse contexto que estamos insistindo na estranha idéia cartesiana da separação entre a ciência e a política. Justamente para compreender o porque de termos certo receio em falar das coisas reais, da sociedade conspurcada por teias e conexões que soam incontroláveis aos parcos sinais que são recebidos pelo exótico cérebro removido do corpo; que passa a tratar o mundo real como algo perigoso, sujo e carente de constante organização, única maneira para não lhe oferecer perigo. Talvez seja porque para agir neste mundo cada indivíduo necessite a cada instante produzir fatos atrás de si, como se fossem degraus sólidos que pudessem suportar o próximo passo. Buscamos, como se fosse de muito bom senso, não confundir as questões epistemológicas (nossas representações do mundo) com as questões ontológicas (a realidade do mundo) (LATOUR, 2001). Tendemos rapidamente a considerar, por exemplo, os ex-alunos do pesquisador como "ruídos" indesejáveis, ou seja, como elementos transgressores da ordem. Não se trata de fazer apologia ou qualquer juízo acerca das ações de cada personagem citado no texto. Trata-se antes de colocar em pauta a hibridização desses dois domínios (epistemologia e ontologia) de forma contingente. $\mathrm{Na}$ ciência real misturar domínios é precisamente o que os cientistas (bons e maus) mais fazem.

Pela perspectiva dos ECC, talvez seja mais fácil compreender porque a noção de cidadania funcione como uma conquista diária, ou para dizer em termos pedagógicos um exercício de cidadania, e ainda porque passamos tanto tempo de nossas vidas nas escolas, ensinando, aprendendo conceitos como razão, consciência e método.

Para Latour (2000), o mais impressionante é que a pretensão ao conhecimento que as bizarras mentes alimentam, prisioneiras em suas borbulhantes cubas de laboratório, produzem um dos mais antigos medos, o medo da tirania das massas. No nosso caso, ex-alunos, governos e toda sorte de pessoas e suas conexões com interesses diversos. É esse medo que nos impede de abandonar toda essa conversa acerca de mentes excisadas, que já sabemos, foi forjada em acordos passados e que se esforça por produzir um mundo científico, relegado inteiramente a ele, frio e inumano, que espreita de longe o outro mundo, o real, rico e inatingível na sua plenitude.

Olhar para o episódio havido na USP sob essa ótica nos ajuda a entender, e talvez produzir, o imenso capital de conhecimentos que a humanidade "economizou" durantes séculos. Há porque pensar no conhecimento científico como um grande banco onde guardamos parte deste precioso "capital cultural", minuciosamente organizado e posto como conhecimento que está "por trás" das ações e pensamentos científicos (OLIVEIRA, 2006). Como já dissemos, temos medo de uma dupla perda: a primeira de que a Ciência com "C" maiúsculo, idealizada por uma mente cartesiana, nos conduza cada vez mais para longe da pulsante sociedade e do mundo real, a segunda é: se a razão e o bom 
senso provenientes do pensamento científico não estiverem presentes, voltaremos aos bárbaros hábitos de uma multidão sem regras onde somente a força pode prevalecer.

É tão assombroso para a mente racional pensar na tomada do poder pela multidão que hoje buscamos com toda a sinceridade científica (re)conectar o pensamento científico ao mundo político e social. Esse desejo tem um sentido importante, pois põe a nu nossos maiores medos e nos motiva a enfrentar os fantasmas que buscam tirar nossa humanidade e nos obrigam a escolher entre um cérebro extirpado e desumano e uma multidão igualmente desumana, pois desprovida de razão. Ou ainda, tentar remendos nessa teia desconexa entre razão e multidão, entre cérebro e corpo, entre ciência e política e entre a arma que protege ao mesmo tempo em que mata. Não é por pouco que Latour (1994) ironiza o esforço de filósofos ao longo da história, quando estes buscam atar estes nós e só conseguem produzir monstros, como tentam também alguns professores.

\section{Os debates, a busca da razão que paira acima da discussão}

Um dos locais mais visitados para encontrar esses monstros que assolam a pretensão à razão absoluta são nos debates, pois neles sempre se espera que, encerradas as discussões, um consenso notadamente superior ao conflito produza a necessária luz para uma sobrevivência harmoniosa dos homens. O que nos esquecemos com freqüência é que destes debates são produzidos acordos que provêm de escolhas baseadas em interesses e no jogo de poder que estabelece o próprio acordo.

Um destes debates foi brilhantemente tratado por Bruno Latour (2001), em seu livro "A Esperança de Pandora", feito com o intuito de marcar mais nitidamente os artifícios que buscam separar ciência e política.

O diálogo escrito por Platão entre Sócrates e Cálicles, pode ser muito esclarecedor para as situações de conflitos e incertezas em que nos encontramos atualmente, em que a ciência é acusada de produzir grandes desastres ambientais, enquanto buscam fazer "somente" pesquisa concretas sobre a natureza das coisas e melhorar o mundo.

As críticas parecem surgir de vários setores da sociedade, em particular aqueles situados do outro lado do campus, sob a égide das ciências humanas, que clamam em palavras de ordem, conforme dito por Latour

Vocês cientistas, quem pensam que são, agora que acreditam que "a Ciência" domina o mundo, querem estender seus tentáculos para a política? Evocando o brado forjado por Platão: Só a razão nos protege contra a força! Ou trazendo para mais próximo dos nossos dias: Só a ciência, que não é feita pelo homem, mas por uma razão inumana irá proteger um estado em constante ameaça de ser feito pela multidão! Toda a questão que se coloca é se devemos ou não manter a conexão entre a "descoberta das leis e regras naturais" e a busca por tornar o estado seguro para seus cidadãos (LATOUR, 2001. p. 28).

Ora! As leis naturais são uma invenção de mentes estropiadas, portanto não são humanas, tal como a cidadania é uma invenção desta mesma mente, que quer se proteger da perigosa multidão desorganizada e desumana. Assim cidadania e conhecimento são edifícios feitos com tijolos provenientes do mesmo lamaçal. Trata-se de uma maquinaria instituída com um propósito claro: domesticar mente e corpo.

Vamos, pelo broquel historiográfico, pinçar alguns pontos de interesse para o tema em questão, apoiando-nos no texto de Bruno Latour. A história que Platão conta é a seguinte: Sócrates após derrotar discursivamente Górgias e Pólo faz seu ataque a Cálicles, que se diz um populista.

\section{Latour diz:}

Estamos tão acostumados a opor Força e Razão e a procurar no Górgias suas melhores exemplificações que nos esquecemos de observar que Sócrates e Cálicles têm um inimigo em comum: o povo de Atenas, a multidão reunida na ágora, falando sem parar, fazendo as leis ao seu 
bel-prazer, agindo como crianças, como doentes (LATOUR, 2001, p 251.).

Uma contribuição importante de Latour para os ECC foi justamente identificar esta particularidade (o medo do povo, do comum, do sujo) no discurso destes dois personagens da história, e tem dolorosa atualidade. Ainda hoje, a epistemologia da ciência busca criar filtros que produzem o afastamento do social, da vida pública dos fazeres científicos (LATOUR, 2004a).

É difícil para a mente educada e organizada, conviver com a incerteza. Mas, se de fato, se quer a multidão fazendo parte da "cidadania", é preciso se acostumar com o barulho que ela produz e estar preparados para muito mais do que um pouco de absurdos (LATOUR, 2001).

Este é o ponto de maior importância para a nossa história, o grande problema que Cálicles e Sócrates tinham com a multidão é o fato de existir um número muito grande de pessoas que a constitui, era isso que assombrava a Sócrates e a Cálicles e é isso que fez da retórica um instrumento tão caro aos atenienses, e aos anseios políticos atuais.

A retórica, diz Sócrates [...] não está preocupada em educar as pessoas reunidas nos tribunais e nas demais assembléias sobre o certo e o errado; tudo o que ela quer é persuadi-las a compreender assuntos tão importantes em tão pouco tempo (LATOUR, 2001).

Não se trata, portanto, de educar e sim convencer as pessoas de assuntos que, por convenção, por acordos, são considerados importantes. Este é o território por excelência da política e do Estado: lidar com a urgência, com a controvérsia. Nesta arena, são tomadas as decisões, no meio do turbilhão são feitos os acordos a serem postos em prática no momento seguinte. Nos encontros em São Petersburgo e Brasília, Lula e Bush dizem que é "hora de tirar as cartas das mangas". E é por isso que o cérebro extirpado não quer deixar tudo nas mãos da multidão. A vida correria à deriva, como uma criança abandonada à própria sorte e prestes a atravessar uma grande e movimentada avenida. O cérebro cartesiano vê na multidão a imagem horrorosa das pessoas atropeladas pela própria ignorância. É isso que faz da sociedade organizada um bem tão caro e daqui vem a crença de que a ordem não existe fora da razão cartesiana e da força política. É neste espaço onde se inventa e reinventa a luta entre a razão e a força. Fica claro para quem são inventadas os dispositivos de controle, tais como as leis, o conhecimento, o estado, as escolas, as prisões - para a multidão! (FOUCAULT, 1987). Aqui está o motivo moral do texto, e um apelo para recuarmos e buscar a encruzilhada na qual se decidiu fazer a separação entre pensamento científico e política. De resto, mostra-nos a quem devemos nos aliar como professores e cientistas. Devemos estar do lado da multidão e, juntos a ela, mostrar as estruturas que se utilizam do poder para "convencer" a todos quais os caminhos a seguir. Mas juntar-se a multidão não tem qualquer sentido salvacionista, pois issonos arrastaria à armadilha de usar a razão para se entrincheirar em uma guerra que só existe nos cérebros extirpados. O que deve ser mantido em mente ao se ler neste texto "se aliar a multidão" é escapar da regra da minoria imposta por Cálicles, segundo o qual, uma pessoa inteligente é superior a 10 mil ignorantes e como para esse autor, a inteligência é um dom natural, é natural que os melhores tenham mais e governem as pessoas inferiores. O modelo que Cálicles usa é o da nobreza, da educação aristocrática. A nobreza é a concepção que confere uma qualidade de distinção, de diferenciação e um status nativo que torna os senhores diferentes da multidão, algo quase inatingível para a maioria. É esta a força que Cálicles atribui ao dom natural de poder político. Uma força que é superior a própria força física dos 10 mil ignorantes (Platão, 1997). É em oposição a esse discurso que separa o mundo tão radicalmente que os ECC se voltam. Mas é também escapar de outra regra, agora inventada por Sócrates, o poder da verdade. Sócrates diz que qualquer refutação é completamente inútil no contexto da verdade, 
Sócrates apela para a grande verdade, que está acima das convenções humanas,

"Não compreendem que esse tipo de astúcia deve ser apropriadamente o tipo dominante e ter liberdade para com os produtos de todas as outras técnicas porque ele CONHECE [...] eis porque o resto deles (o povo) só é adequado para o trabalho escravo, e deve por direito ser subordinado ao treinamento e à medicina" (PLATÃO, 1997, p. 142).

Temos, embora de forma muito resumida, uma idéia do jogo de elisão da multidão em que tanto o populista (Górgias) quando o cientista (Sócrates) se ocupam. Um único homem pode prevalecer sobre qualquer outro, tanto no "contexto da aristocracia", quanto no "contexto da verdade". Assim, quando falamos denossas posições deveros professoresaliados à multidão, queremos dizer que existem articulações que nos querem aprisionados na armadilha que joga, de um lado a FORÇA, não da multidão como temia Cálicles, mas de um homem contra a multidão; e de outro, a RAZÃO (verdade, fato, natureza), não de um homem contra outro, mas como uma lei natural que é superior ao próprio homem.

Essa estratégia está indissociavelmente conectada a algo muito difícil de ser feito: abandonar qualquer pretensão a um pensamento racional ou a uma ciência com " $C$ " maiúsculo, feitos pelo cérebro extirpado, busca-se rejeitar qualquer poder que hegemonicamente advogue o direito de dizer aos outros o que fazer, dado que suas verdades baseiam-se nas suas próprias práticas. Este sonho representa algo como: a ciência perdendo o medo da multidão, por um motivo muito simples: a ciência não é e não lida com cérebros em tubos de ensaio, mas com pessoas que vivem apressadas, são inconstantes, têm seus valores, seus crenças e possuem uma racionalidade contingente e específica.

Não se trata de ser inimigo das ciências ou da política, mas, sem fingir pertencer a uma ou a outra, tentar conviver criticamente com as duas. Ainda estamos lutando, nos tempos dos múltiplos combustíveis com este dilema forjado por Platão: Como ter uma ciência e uma democracia ao mesmo tempo? Pelo acordo firmado entre Sócrates e Cálicles isto não é possível. Como a razão, que mantém seus fundamentos numa conexão artificial com o mundo, pode conviver com a multidão tomando decisões acaloradas?

Disso resultaria, pensa o cérebro aleijado, a completa inutilidade de todo o aparato tecnológico montado para mantê-lo ligado ao mundo, tal como escolas, laboratórios, hospitais, política, sociedade, cidadania, ciência... A mente cartesiana acredita, com toda a certeza, que desprovida do paternalismo dos peritos, guardiões do conhecimento racional e da força política do convencer, - necessários para cuidar de seus cidadãos - cairemos na mais horrorosa guerra civil: todos contra todos.

Para domar tais feras, diz Górgias, é preciso fazer como se faz com o tigre, capturá-lo bem cedo e mediante encantamentos e fórmulas, convencêlas de que a igualdade, o respeito às regras e às instituições são as mais belas formas de felicidade. Só assim a sociedade inventada por Platão poderá se livrar da turba incontrolável de quase humanos que invadem os laboratórios e de lá saem cada um com um pedaço.

Tudo isso pode estar soando um tanto ridículo para nós, já que ninguém quer ser identificado nem com o cérebro que, isolado em uma cuba, vê o mundo de longe, nem com um político, no mais escandaloso uso da retórica e, muito menos, com vândalos. Somos homens e mulheres feitos e não escravos, crianças e ignorantes reunidos na ágora romana, todos falando ao mesmo tempo, não é mesmo? Já sabemos que, na vida chã, lida-se com situações extremamente ásperas, urgentes e não se tem garantias de que as decisões tomadas vão funcionar. Tampouco somos ingênuos em pensar que o cientista entra em seu laboratório já com as idéias do que fazer completamente pré-concebidas e com um toque de mágica inventa coisas maravilhosas. Sabemos que o trabalho é árduo, moroso, carregado de avanços e retrocessos e dependente da capacidade do cientista de convencer outras pessoas de que seu 
invento é importante, e isso, já sabemos, depende inteiramente dos interesses que estão em jogo.

Em última análise, nunca fomos de fato uma turba bárbara, somos humanos.

\section{A guisa de conclusão}

Então, para finalizar este texto, vale direcionar os olhares para o nosso exemplo. Ele foi utilizado como uma alavanca para tratar de uma situação que, penso, não é novidade para os cientistas que escrevem os outros textos desse número especial da revista. O cientista com "c" minúsculo está vivo e em articulação com o mundo natural. Sabemos agora, penso, que a ciência com "C" maiúsculo contribui pouco para entender melhor o mundo, posto que é uma invenção preocupada apenas em formar um pensamento elitista e racional, fundamentada no convencimento sem compreensão, que deixa muda a multidão classificada no jogo da epistemologia científica como: financiamentos, interesses, jogos de poder, disputas por patentes e projetos... Mesmo que se queira, a ciência, ao se ocupar das suas tarefas diárias, práticas e controvertidas, não dá a mínima para o ódio que Platão nutria do mundo feito rotineiramente pelas mãos humanas. Os cientistas estão inextricavelmente imersos na política de fazer ciência.

Temos um grande problema em nossas mãos: o "anseio cartesiano" sempre foi utilizar-se do recurso da persuasão para convencer as pessoas a viver na sociedade, isso significaria ajustar-se ao exterior organizado, - que exclui a multidão -, em vez da cidadania tão sonhada, vamos cada vez mais fundo na crença dessa sociedade. O projeto da razão é fazer os indivíduos pensarem que quanto mais educação e ciência tiverem mais autônomos serão, enquanto mergulham cada vez mais fundo na dependência da razão científica e em levar uma vida sujeitada à docilidade e ao isolamento.

Percorrida a argumentação que pretendia para esse texto, retoma-se invertida a pergunta feita no início: Qual seria a vantagem de insistir na idéia de ciência como uma sucessão histórica de fatos? Nenhuma! O que faremos, então, como cientistas? Ciência! Porém, longe dos critérios normativos da análise epistemológica que querem convencer o cientista de que ele é algo vazio de sua própria condição política e humana, com falta de algo que precisa ser preenchido com razão, ética e isolamento. Se a ciência falha, o que se faz? Pela ótica cartesiana dá-se mais ciência, produz-se mais provas, de forma que a ciência se torna remédio para seus próprios males. Somente a crença no cérebro cartesiano atua nesta dimensão, é somente na estranha crença de que através dela mesma se podem resolver os problemas.

O pavor que provoca pensar em bárbaros invadindo os laboratórios da Ciência retirou da multidão a moralidade básica que as necessidades de convivência e de sociabilidade impôs durante milhões de anos aos "animais" darwinianos. A filosofia moral, diz Latour, é um narcótico tão vicioso quanto o pensamento científico livre de sua política, que ao final resultaria na equação:

\section{razão + moralidade - multidão $=$ estado impossível}

Essa equação de cientista maluco, a qual tenta restituir à multidão o que lhe foi tirado, acrescenta o pensamento absolutista (razão + moralidade) que torna o estado impossível e retira as mediações práticas (multidão) pelas quais as pessoas fazem bom uso de seus conhecimentos relativos e de suas moralidades relativas para conseguir sobreviver nas duras condições da vida.

Até agora estivemos discutindo a maquinaria da produção de uma forma especializada de política e uma forma especializada de ciência: Disso resultou uma política ruim, pois amarrada nas estruturas racionais, e uma ciência ainda pior, pois desenraizada da condição humana. Mas se deixarmos o adjetivo cientifico livre deste acordo, talvez possamos achar outras formas de definir "ciência".

O primeiro sentido é o que me refiro ao longo desta fala (LATOUR, 2001, p. 296;1997, p. 3): o da Ciência com "C" maiúsculo, o ideal da transmissão 
de informações sem discussão ou deformação, muito próxima da imagem fantástica do cientista abnegado que se enfurna em seu laboratório e de lá só tira certezas.

Esta [...] não é uma descrição do que os cientistas fazem [...] é uma ideologia que nunca teve qualquer outro uso nas mãos do epistemologista, senão o de oferecer um substituto para a discussão pública. Ela sempre foi uma arma política para abolir as coações da política. [...] tendo sido projetada como arma [...] tem apenas um uso: "Mantenha a boca fechada". (LATOUR, 2001, p. 296).

A ciência com "C" maiúsculo pode ser entendida como uma forma de discurso, que permite eclipsar o discurso público, a conversa popular, a lengalenga mundana, os rumores ociosos, o mostruário indefinido da subjetividade. Nesse primeiro sentido, dizer que um dado qualquer é "científico", quer dizer que nada mais existe para discutir (LATOUR, 1997). Qualquer coisa que atravessa o meio da vida comum e tentar detê-la é tão inútil quanto entrar no mar e tentar parar uma onda com as mãos.

No segundo sentido, nãointeressa abolir a política, "não porque é apolítico ou porque é politizado, mas porque lida com questões inteiramente diversas" (LATOUR, 2001, p. 297), com direito a espionagem, política, manipulação de informações pela mídia... etc. Nesse sentido, o adjetivo "científico" quer dizer quase o oposto. Pela perspectiva dos ECC estabelecem-se novas conexões, novos acessos a entidades das quais jamais se falou ou viu e que começam a formar um universo de discursos novos no interior das comunidades científicas de origem.

A ciência com "c" minúsculo não interrompe a discussão, bem pelo contrário, deixa-a mais complexa. Ora, "é de muitas controvérsias, problemas, assunção de riscos e imaginação e de uma "vascularização" com o resto do coletivo tão rico e tão complexo quanto possível” (LATOUR, 2001, p. 298) que a ciência precisa. Ou melhor, como diz Lenoir (2005), “é nesse coletivo que elas produzem e reproduzem a textura viva da sociedade"
É nesta ciência que vemos os cientistas e professores de ciência se envolverem (OLIVEIRA, 2005). Necessita-se o tempo todo correr atrás de financiamentos, de convencer os colegas acerca de seus projetos, de passar horas trabalhando, de aliciar estagiários, de obter o interesse da multidão, das multinacionais, etc. É neste mundo "sujo" que vivemos, não no mundo perfeito e sobrenatural que Platão quis inventar ou vendo-o atrás de uma redoma de vidro, como no cérebro cartesiano. É no mundo humano e feito por pessoas com seus interesses relativos em que vivemos e fazemos ciência.

\section{Referências}

COLLINS, H.; KUSCH, M. The shape of actions: what human and machines can do. Cambridge: MIT Press, 1998.

DÁVILA, S. Enviados de Bush vêm fortalecer "amigos". Folha de São Paulo, São Paulo, 6 fev. 2007. Caderno Mundo, p. A12.

DESCARTES, R. Discurso do método: as paixões da alma. 4. ed. São Paulo: Nova Cultural, 1989.

FOUCAULT, M. As palavras e as coisas: uma arqueologia das ciências humanas. 8.ed. São Paulo: Martins Fontes, 1999.

Vozes, 1987.

Vigiar e punir: nascimento da prisão. Petrópolis:

GORE, J. M. Foucault e Educação: fascinantes desafios. In: SILVA, T. T. (Org.). O sujeito da educação: estudos foucaultianos. Petrópolis: Vozes, 1994.

GRAY, J. Cachorros de palha. Rio de Janeiro: Record, 2006.

GROSSBERG, L. Cultural studies. Nova York/Londres: Routledge, 1992

KOYRÉ, A. Estudos de história do pensamento científico. Rio de Janeiro: Forense, 1982.

LATOUR, B. A esperança de pandora: ensaios sobre a realidade dos estudos científicos. Bauru: EDUSC, 2001.

As variedades do "científico". Folha de São

Paulo, São Paulo, 2 nov. 1997. Caderno Mais, p. 3.

. Jamais fomos modernos. Rio de Janeiro: Editora

34, 1994. 
Ciência em ação: Como seguir cientistas e engenheiros sociedade afora. São Paulo: EdUNESP, 2000 .

Politicas da natureza: como fazer ciência na democracia. Bauru: EDUSC, 2004a.

. Why has critique run out of stean? From matters of fact to matters of concern. Critical Inquiry, Chicago, v. 30, n. 2., p. 225-249, 2004.

Por uma antropologia do centro. Mana, Rio de Janeiro, v. 10, n. 2, p.397-414, 2004.

LATOUR, B.; WOOLGAR, S. A vida de laboratório: a produção dos fatos científicos. Rio de Janeiro: Relume Dumará, 1997.

LE GOFF, J. História e memória. São Paulo: UNICAMP, 1992.

LENOIR, T. Instituindo a ciência: a produção cultural da disciplinas científicas. São Leopoldo: EdUNISINOS, 2005a.

- Tecnohumanismo: réquiem para o ciborgue. In: REGNER, A. C. K. P.; ROHDEN, L. A filosofia e a ciência redesenham horizontes. São Leopoldo: EdUSINOS, 2005b.

LOCKE, J. Dois tratados sobre o governo. São Paulo: Martins Fontes, 1998.

MATTELART, A. Introdução aos estudos culturais. São Paulo: Parábola Editorial, 2004.
MICHAEL, H.; NEGRI, A. Império. 5.ed. Rio de Janeiro: Record, 2003.

MONDIN, B. Curso de Filosofia. 3.ed. São Paulo: Edições Paulinas, 1981. v. 2.

OLIVEIRA, M. A. A ciência do laboratório escolar produzindo o "por trás": análise de um experimento de química no ensino médio. In: ENCONTRO NACIONAL DE ENSINO DE QUÍMICA, 13., 2006, Campinas. Anais... Campinas: Unicamp, 2006. CD-ROM.

- Enunciados científicos nos laboratório de ciências do ensino médio. 2005. Tese (Doutorado em Educação) - Universidade do Vale do Rio dos Sinos, São Leopoldo.

PLATÃO. Gorgias. Lisboa: Edições 70, 1997.

SERRES, M. Cinco entrevistas com Bruno Latour. São Paulo: Unimarco, 1999.

VEIGA-NETO, A. J. A ordem da disciplina. 1996. Tese (Doutorado em Educação) - Universidade Federal do Rio Grande do Sul., Porto Alegre.

WOLFOWITZ, P. Elogia produção de etanol do país. Folha de São Paulo, São Paulo, 16 fev. 2007. Caderno Dinheiro, p. B9.

WORTMANN, M. L. C.; VEIGA-NETO, A. ECC \& Educação. Belo Horizonte: Autêntica, 2001. 